\title{
Non-Controlling Minority Shareholdings and Collusion
}

\author{
Samuel de Haas ${ }^{1}$. Johannes Paha ${ }^{1,2,3}$
}

Published online: 9 May 2020

(c) The Author(s) 2020

\begin{abstract}
This article merges theoretical literature on non-controlling minority shareholdings (NCMS) in a coherent model to study the effects of NCMS on competition and collusion. The model encompasses both the case of a common owner holding shares of rival firms as well as the case of cross ownership among rivals. We find that by softening competition, NCMS weaken the sustainability of collusion under a greater variety of situations than was indicated by earlier literature. Such effects exist, in particular, in the presence of an effective competition authority.
\end{abstract}

Keywords Collusion · Common ownership · Cross ownership · Minority shareholdings

\section{Introduction}

Corporations sometimes acquire a minority (less than 50\%) equity stake in a rival firm that allows them to share in the profitability of the rival without obtaining control: The buyer acquires a passive interest; see Salop and O'Brien (2000), Tzanaki (2015), and Nain and Wang (2018) for evidence of such acquisitions. Similarly, the majority shareholder of a firm may decide to acquire a non-controlling share in a rival firm (common ownership).

Competition authorities have shown an interest in the economic effects of the acquisition of non-controlling minority shareholdings (NCMS) of both types. For

Earlier versions of this article were circulated under the title "Partial cross ownership and collusion".

Samuel de Haas

samuel.de-haas@wirtschaft.uni-giessen.de

Johannes Paha

johannes.paha@wirtschaft.uni-giessen.de

1 Chair for Industrial Organization, Regulation and Antitrust, Justus-Liebig-University, Licher Strasse 62, 35394 Giessen, Germany

2 Stellenbosch University, Stellenbosch, South Africa

3 Potsdam University, Potsdam, Germany 
example, in July 2014 the EU issued a White Paper that discusses an amendment of the current EU Merger Regulation towards assessing NCMS. Since then, especially common ownership has received increasing attention.

Theoretical literature such as Reynolds and Snapp (1986), Flath (1991), Flath (1992), Malueg (1992), and Gilo et al. (2006) has studied the effects of NCMS on firms' profits and the sustainability of collusion under a variety of assumptions with respect to a number of key parameters such as firms' profit function, their strategic variables (prices versus quantity), and the degree of product differentiation. This diversity of assumptions constitutes an impediment to the comparability of different articles' results.

Our article integrates these earlier models into a more comprehensive one, which fills a gap in the literature because we analyze several combinations of assumptions that have not been studied jointly by prior literature. We also provide analytic proofs for effects that have been established only numerically by prior literature.

The model confirms two insights: First, NCMS of firm $i$ in firm $j$ raise firms' profits in competition. These are the profits that are made when every firm plays its best response to the other firm's choice of its strategic variable. But this increase in competitive profits also increases the incentive to deviate from collusion. This is because the deviator $i$ 's profits in the punishment phase will be higher because of the reduced intensity of competition. Second, NCMS decrease firm $i$ 's incentive to deviate because firm $i$ (or its majority shareholder) would then receive lower dividends from the cheated firm $j$. Hence, minority shareholdings increase the deviation incentive if the first effect prevails over the second; as has been shown by Malueg (1992) for convex demand.

We advance the literature in two directions. First, our model is the first to study analytically how a competition authority influences the effect of minority shareholdings on the sustainability of collusion. We find that the collusion-destabilizing effect of NCMS is particularly strong in the presence of an effective competition authority. This effect can be observed even when demand is non-convex.

Second, prior literature has typically concentrated on the question of how firm $i$ 's shares in firm $j$ affect $i$ 's decision whether to deviate from collusion. In addition, we show that firm $j$ 's shareholdings in firm $i$ destabilize collusion by raising firm $i$ 's critical discount factor whenever the cross shareholdings raise the firms' profits in competition. This indicates that minority shareholdings destabilize collusion under a wider set of assumption than was suggested by earlier literature.

The article is structured as follows. Section 2 shows how the present study contributes to the existing literature. Section 3 provides the model and studies the effects of NCMS on firms' stage game profits. Section 4 analyzes the effects of NCMS on the sustainability of collusion. Section 5 adds the competition authority. Our results are robust to changes in the assumptions about firms' profit functions, which might either model cross ownership or common ownership, as is demonstrated in Sect. 6. Section 7 concludes the article. Proofs are provided in the "Appendix". 


\section{Literature Review}

Reynolds and Snapp (1986) established that in a static Cournot model with symmetric firms and homogeneous products NCMS make it a best response for the firms to restrict aggregate output and raise aggregate profits. ${ }^{1}$ Malueg (1992) later extended this model to an infinitely repeated game and showed that NCMS may have an ambiguous impact on the stability of collusion by reducing the short-run gain from cheating while, at the same time, softening the long-run punishment that is imposed on the deviating firm.

In addition, Flath $(1991,1992)$ presented a static model to study the effects of NCMS on firms' profits not only in Cournot competition with homogeneous products, but also in Bertrand competition with either differentiated or homogeneous products. ${ }^{2}$ Unfortunately, these results cannot be compared to those of Reynolds and Snapp (1986) or Malueg (1992). This is because Flath (1991) assumed that the firms maximize a profit function that is commonly used for cross ownership whereas Reynolds and Snapp (1986) and Malueg (1992) assume that the firms maximize a profit function that is commonly used to model common ownership. We implement our model under both assumptions to enhance comparisons of these earlier contributions.

Gilo et al. (2006) extended the model of Flath (1991) to a dynamic game, which allows them to study the effect of minority shareholdings on collusion. They focus on a Bertrand model with homogeneous products where minority shareholdings cannot raise the profits that the firms make in competition, which however played a prominent role in the analysis of Malueg (1992). We extend their model by assuming also Cournot competition and Bertrand competition with differentiated products where NCMS raise firms' profits in competition. Contrary to Gilo et al. (2006), this points towards a variety of situations where NCMS hinder collusion.

We add a new element to this strand of the literature by assuming that a competition authority behaves along the lines of Aubert et al. (2006): Collusion may be detected with a certain probability and penalized thereafter. We show that in the presence of an effective competition authority NCMS may weaken the sustainability of collusion even under conditions where the literature cited above suggested a stabilizing effect of NCMS on collusion; for example, NCMS are found to destabilize collusion also for non-convex demand, which contributes to Malueg (1992), and even for Bertrand competition with homogeneous products, which extends the results of Gilo et al. (2006).

The present article along with the literature cited above concentrates on acquisition decisions of NCMS that are driven by the rationale of receiving a dividend and raising the acquirer's expected profits. Karle et al. (2011) argued that NCMS

\footnotetext{
1 Empirical evidence of the effects of cross ownership and the related issue of common ownership on firms' profits in competition has been provided, for example, by Azar et al. (2016), Trivieri (2007), and Nain and Wang (2018).

2 A related analysis was conducted by Reitman (1994) in a conjectural variations model that was based on the analysis of joint ventures that was conducted by Kwoka (1992).
} 
may also be driven by efficiency considerations such as the generation of economies of scope in the production process. Ouimet (2013) concentrated on NCMS that are made to provide a financially constrained target firm with additional funds for solving hold-up problems when engaging in joint investment projects. López and Vives (2016) analyzed the effect of cross ownership on firms' R\&D-efforts. Our model indicates that even NCMS that were acquired to only raise the profits of the acquirer may have pro-competitive effects by disrupting collusion. To make this point most clearly we abstract from further efficiency considerations.

\section{The Model}

Section 3.1 presents the setup of the model. Section 3.2 establishes the effects of minority shareholdings on firms' stage game profits.

\subsection{Setup}

The model assumes two cost-symmetric, risk-neutral firms $i, j \in\{1,2\}$. The majority owner of firm $i$ may hold a minority stake $\alpha_{i}$ in firm $j$ while the majority owner of firm $j$ may hold a minority stake $\alpha_{j}$ in firm $i$. The stakes may be asymmetric $\left(\alpha_{i} \neq \alpha_{j}\right)$, and they are assumed to have been chosen prior to the game analyzed here, which is in line with Reynolds and Snapp (1986), Malueg (1992), and Gilo et al. (2006).

The firms $i$ and $j$ play an infinitely repeated game with the objective of maximizing the discounted sum of their majority owners' individual profits. The discount factors are denoted $\delta_{i}, \delta_{j} \in(0,1)$. In each period, the firms choose a product market strategy $s_{i}, s_{j} \in\{c, k\}$ with $c$ indicating best-response behavior in the product market while $k$ represents the collusive choice of their strategic variable. We analyze the firms' choice of $s_{i}, s_{j}$ in Sect. 4 .

Our analysis is conducted in the three models that were studied by Flath (1991): Cournot competition; Bertrand competition with differentiated products; and Bertrand competition with homogeneous products. Therefore, the product market profit/ operating profit $\pi_{i}$ of firm $i$ is a function of the firms' strategic variables - quantities in Cournot competition, and prices in Bertrand competition - and these strategic variables are functions of firms' endogenous choice of $s_{i}, s_{j}$ and the exogenous shareholdings $\alpha_{i}, \alpha_{j}$. The profits can be expressed as $\pi_{i}\left(q_{i}\left(q_{j}, s_{i}, \alpha_{i}, \alpha_{j}\right), q_{j}\left(q_{i}, s_{j}, \alpha_{j}, \alpha_{i}\right)\right)$ in Cournot competition and $\pi_{i}\left(p_{i}\left(p_{j}, s_{i}, \alpha_{i}, \alpha_{j}\right), p_{j}\left(p_{i}, s_{j}, \alpha_{j}, \alpha_{i}\right)\right)$ in Bertrand competition.

In Sect. 3.2, we determine the firms' collusive strategies and their non-collusive best responses in the product market. Firms' best responses are initially obtained under the assumption of equation (1). Firm $i$ is assumed to maximize its majority owner's payoff $\tilde{\pi}_{i}$ : Firm $i$ 's product market profit $\pi_{i}$, minus the dividend $\alpha_{j} \pi_{i}$ that is paid to firm $j$, plus the dividend $\alpha_{i} \pi_{j}$ that is received from firm $j$ (Reynolds and Snapp 1986; Malueg 1992):

$$
\max \tilde{\pi}_{i}=\left(1-\alpha_{j}\right) \pi_{i}+\alpha_{i} \pi_{j}
$$


Flath (1991, 1992), Gilo et al. (2006), and Shelegia and Spiegel (2012) modeled cross ownership and used a different profit function where the firms maximize their accounting profits: $\hat{\pi}_{i}=\pi_{i}+\alpha_{i} \hat{\pi}_{j}$. In Sect. 6 , we discuss the exact interpretation of this profit function, and we show that the effects that are presented in this article are qualitatively identical for both profit functions.

Plugging the collusive strategies and competitive best responses into the profit functions for all four combinations of $s_{i}$, $s_{j}$ yields values of the profits that are dependent on the value of the shareholdings $\alpha_{i}$ and $\alpha_{j}$. For reasons of conciseness, we use indices to denote the strategy combinations $\left(s_{i}, s_{j}\right): c$ for $(c, c) ; k$ for $(k, k) ; d$ if $i$ is the deviator in $(c, k)$; and $-d$ if $i$ is the cheated firm in $(k, c)$. Notation is further explicated in Sect. 3.2. In the models that we analyze, the inequalities that are shown in (2) apply, which impose a prisoner's dilemma structure on the game:

$$
\pi_{i, d}>\pi_{i, k}>\pi_{i, c} \geq \pi_{i,-d} \text { and } \pi_{i, d}+\pi_{i,-d}<2 \pi_{i, k} \quad \text { for all } i \in\{1,2\} .
$$

The total payoffs $\tilde{\pi}_{i, c}, \tilde{\pi}_{i, k}, \tilde{\pi}_{i, d}$ of majority owner $i$ can be expressed as in (3)-(5):

$$
\begin{gathered}
\tilde{\pi}_{i, c}=\left(1-\alpha_{j}\right) \pi_{i, c}+\alpha_{i} \pi_{j, c} \\
\tilde{\pi}_{i, k}=\left(1-\alpha_{j}\right) \pi_{i, k}+\alpha_{i} \pi_{j, k} \\
\tilde{\pi}_{i, d}=\left(1-\alpha_{j}\right) \pi_{i, d}+\alpha_{i} \pi_{j,-d} .
\end{gathered}
$$

\subsection{The Stage Game}

This subsection establishes firms' best responses and equilibrium profits in Cournot competition, Bertrand competition with differentiated products, and Bertrand competition with homogeneous products. It demonstrates the effects of $\alpha_{i}, \alpha_{j}$ on the firms' stage game profits.

Cournot competition In Cournot competition, the payoff $\tilde{\pi}\left(q_{i}\left(q_{j}, s_{i}, \alpha_{i}, \alpha_{j}\right)\right.$, $\left.q_{j}\left(q_{i}, s_{j}, \alpha_{j}, \alpha_{i}\right)\right)$ of firm $i$ 's majority owner, which will be abbreviated as $\tilde{\pi}\left(q_{i}, q_{j}\right)$, is a function of the outputs $q_{i}$ and $q_{j}$. The term $\tilde{q}_{i}^{R}\left(q_{j}, \alpha_{i}, \alpha_{j}\right)$ denotes firm $i$ 's reaction function after choosing $s_{i}=c$ if it maximizes payoff function $\tilde{\pi}_{i}$. The arguments $q_{j}$, $\alpha_{i}$, and $\alpha_{j}$ of the best-response function $\tilde{q}_{i}^{R}$ are sometimes dropped for reasons of conciseness. The firms are said to compete if both play their best responses - $\left(s_{i}, s_{j}\right)=(c, c)$ - which generates the payoff $\tilde{\pi}_{i}\left(\tilde{q}_{i}^{R}\left(\tilde{q}_{j}^{R}, \alpha_{i}, \alpha_{j}\right), \tilde{q}_{j}^{R}\left(\tilde{q}_{i}^{R}, \alpha_{j}, \alpha_{i}\right)\right)$, which we abbreviate as $\tilde{\pi}_{i, c}\left(\alpha_{i}, \alpha_{j}\right)$. The discussion below relies on a result that is summarized in Lemma 1:

Lemma $1 \frac{\partial \pi_{i, c}}{\partial \alpha_{i}}<0$ and $\frac{\partial \pi_{i, c}}{\partial \alpha_{j}}>0$ if $\frac{\partial q_{i}^{R}}{\partial q_{j}}<0$. 
Proof See "Appendix 1"3

Lemma 1 implies that the product-market profits $\pi_{i, c}$ of firm $i$ in competition fall if the majority owner of firm $i$ holds a higher share $\alpha_{i}$ in firm $j$. This occurs if quantities are strategic substitutes: $\partial q_{i}^{R} / \partial q_{j}<0$, with $q_{i}^{R}\left(q_{j}\right)=\tilde{q}_{i}^{R}\left(q_{j}, 0,0\right)$ denoting firm $i$ 's reaction function when $\alpha_{i}, \alpha_{j}=0$; when maximizing product market profits $\pi_{i}$ only. Firm $i$ finds it optimal to reduce both its own output $\left(\partial \tilde{q}_{i}^{R} / \partial \alpha_{i}<0\right)$ and its productmarket profits $\pi_{i, c}$ in order to raise the total payoff $\tilde{\pi}_{i, c}$ of its majority owner by raising the other firm's profit $\pi_{j, c}$, so that the majority owner of firm $i$ receives a higher dividend from firm $j$ (Reynolds and Snapp 1986). Conversely, a higher value of $\alpha_{j}$ raises $\pi_{i, c}$ : The product-market profits $\pi_{i, c}$ of firm $i$ in competition rise if the majority owner of firm $j$ holds a higher share $\alpha_{j}$ in firm $i$.

As in Malueg (1992) and Gilo et al. (2006), the firms are assumed to collude in the product market by setting a 50\%-share of the monopoly output: $q_{i, k}=q_{j, k}=Q_{k} / 2$. Because the collusive output is independent of $\alpha_{i}$ and $\alpha_{j}$, the collusive profits are also independent of the value of shareholdings: $\partial \pi_{i, k} / \partial \alpha_{i}=0, \partial \pi_{i, k} / \partial \alpha_{j}=0$.

Deviation profits are defined as $\tilde{\pi}_{i, d}\left(\alpha_{i}, \alpha_{j}\right)=\tilde{\pi}_{i}\left(\tilde{q}_{i}^{R}\left(q_{j, k}, \alpha_{i}, \alpha_{j}\right), q_{j, k}\right)$ and $\tilde{\pi}_{j,-d}\left(\alpha_{i}, \alpha_{j}\right)=\tilde{\pi}_{j}\left(q_{j, k}, \tilde{q}_{i}^{R}\left(q_{j, k}, \alpha_{i}, \alpha_{j}\right)\right)$ : Firm $i$ plays its best response while firm $j$ sets the agreed-upon output. Lemma 2 establishes the effect of $\alpha_{i}$ on the product market profits in a deviation period:

Lemma $2 \frac{\partial \pi_{i, d}}{\partial \alpha_{i}}<0$ and $\frac{\partial \pi_{j,-d}}{\partial \alpha_{i}}>0$.

Proof See "Appendix 1".

If firm $i$ deviates from collusion, its majority owner receives a lower dividend from firm $j$ as compared to continued collusion $\left(\alpha_{i} \pi_{j,-d}<\alpha_{i} \pi_{j, k}\right)$. The higher is the value of $\alpha_{i}$ the stronger is this effect, and the lower is the payoff $\tilde{\pi}_{i, d}$ that the majority owner of firm $i$ earns after the payment of dividends. Accordingly, minority shareholdings $\alpha_{i}>0$ induce the deviating firm $i$ to set a lower deviation quantity than with $\alpha_{i}=0$ and, thus, to earn lower deviation profits in the product market. This leaves higher profits for firm $j: \partial \pi_{j,-d} / \partial \alpha_{i}>0$.

Bertrand competition with differentiated products Similar effects are found when we assume Bertrand competition with differentiated products. The payoff $\tilde{\pi}\left(p_{i}, p_{j}\right)$ of firm $i$ 's majority shareholder is a function of the prices $p_{i}$ and $p_{j}$ of the two firms. Let $\tilde{p}_{i}^{R}\left(p_{j}, \alpha_{i}, \alpha_{j}\right)$ denote the best-response function of firm $i$ after choosing $s_{i}=c$. The firms compete when both play their best responses, making profits $\tilde{\pi}_{i, c}\left(\alpha_{i}, \alpha_{j}\right)=\tilde{\pi}_{i}\left(\tilde{p}_{i}^{R}\left(\tilde{p}_{j}^{R}, \alpha_{i}, \alpha_{j}\right), \tilde{p}_{j}^{R}\left(\tilde{p}_{i}^{R}, \alpha_{j}, \alpha_{i}\right)\right)$. Our analysis relies on Lemma 3:

\footnotetext{
3 The proof of Lemma 1 relies on the assumption of $\partial q_{i}^{R} / \partial q_{j}<0$, which applies for the demand for homogeneous products that were assumed by Flath (1991) and Malueg (1992) as well as for several Cournot models with differentiated products. The analysis of the less common case with $\partial q_{i}^{R} / \partial q_{j} \geq 0$ is left for future research.
} 
Lemma $3 \frac{\partial \pi_{i, c}}{\partial \alpha_{j}}>0$ and $\frac{\partial \pi_{i, c}}{\partial \alpha_{i}}\left\{\begin{array}{l}>0 \text { if } \alpha_{i}<\alpha_{j}+A \\ \leq 0 \text { if } \alpha_{i} \geq \alpha_{j}+A .\end{array}\right.$

Proof See "Appendix 1".

As compared to Cournot competition, firm $i$ 's competitive profit rises even for unilateral increases of its share $\alpha_{i}$ in firm $j$ as long as the shares are not too asymmetric: $\alpha_{i}<\alpha_{j}+A$. The exact value of the threshold $A$ depends on the functional form of demand as is shown in the proof of Lemma 3. This effect emerges because in a Bertrand model with differentiated products prices are strategic complements. Shareholdings $\alpha_{i}$ induce firm $i$ to raise its price, and firm $j$ follows suit. Therefore, even a somewhat asymmetric increase in $\alpha_{i}$ may cause an increase in both firms' profits. However, for $\alpha_{i} \geq \alpha_{j}+A$ the reduction in output that results from the higher prices becomes the dominant force, which leads to $\partial \pi_{i, c} / \partial \alpha_{i} \leq 0$.

The firms are assumed to collude in the product market by setting the same prices $p_{i, k}$ and $p_{j, k}$ that a jointly profit-maximizing monopolist would set. These prices are independent of $\alpha_{i}$ and $\alpha_{j}$, which implies $\partial \pi_{i, k} / \partial \alpha_{i}=0$ and $\partial \pi_{i, k} / \partial \alpha_{j}=0$. The deviation payoffs are defined as $\tilde{\pi}_{i, d}\left(\alpha_{i}, \alpha_{j}\right)=\tilde{\pi}_{i}\left(\hat{p}_{i}^{R}\left(p_{j, k}, \alpha_{i}, \alpha_{j}\right), p_{j, k}\right)$ and $\tilde{\pi}_{j,-d}\left(\alpha_{i}, \alpha_{j}\right)=\tilde{\pi}_{j}\left(p_{j, k}, \tilde{p}_{i}^{R}\left(p_{j, k}, \alpha_{i}, \alpha_{j}\right)\right)$. "Appendix 1" shows that Lemma 2 $\left(\partial \pi_{i, d} / \partial \alpha_{i}<0\right.$ and $\left.\partial \pi_{j,-d} / \partial \alpha_{i}>0\right)$ applies also in Bertrand competition with differentiated products.

Bertrand competition with homogeneous products In Bertrand competition with homogeneous products "both firms set prices equal to marginal cost regardless of the state of any partial cross shareholding" (Flath 1991): The firms make zero profits $\left(\pi_{i, c}=0, \pi_{j, c}=0, \partial \pi_{i, c} / \partial \alpha_{i}=0\right.$, and $\left.\partial \pi_{j, c} / \partial \alpha_{i}=0\right)$, and minority shareholdings have no effect on firms' profits in competition. Similarly, the collusive and the deviation profits are also independent of the value of minority shareholdings: $\partial \pi_{i, k} / \partial \alpha_{i}=0 ; \partial \pi_{j, k} / \partial \alpha_{i}=0 ; \partial \pi_{i, d} / \partial \alpha_{i}=0 ; \partial \pi_{j,-d} / \partial \alpha_{i}=0$. A deviating firm would cut the collusive price marginally and earn $\pi_{i, d}=2 \pi_{i, k}$, while the betrayed firm would earn $\pi_{j,-d}=0$.

\section{The Dynamic Game}

Using the framework introduced in Sect. 3, we study the effects of NCMS on the sustainability of collusion. Section 4.1 points out the forces that determine the effect of $\alpha_{i}$ on the critical discount factor $\tilde{\delta}_{i}^{*}$ in a general model. Section 4.2 applies this analysis to specific models of competition. Section 4.3 analyzes how minority shareholdings $\alpha_{j}$ of firm $j$ 's majority shareholder in firm $i$ affect the critical discount factor $\tilde{\delta}_{i}^{*}$ of firm $i$.

\subsection{The Critical Discount Factor}

Collusion is profitable for the firms if inequality (6) is satisfied. Collusion is sustainable if inequality (7) applies: 


$$
\begin{gathered}
\pi_{i, k}-\pi_{i, c}>0 \quad \forall \quad i \in\{1,2\} ; \\
\frac{\tilde{\pi}_{i, k}}{1-\delta_{i}}>\tilde{\pi}_{i, d}+\frac{\delta_{i}}{1-\delta_{i}} \tilde{\pi}_{i, c} \quad \forall \quad i \in\{1,2\} .
\end{gathered}
$$

In line with Malueg (1992), Aubert et al. (2006), and Gilo et al. (2006), the present value of deviation payoffs-the right-hand side of (7)-assumes a grim trigger strategy (Friedman 1971). With the use of equation (1), $\tilde{\pi}_{i}=\left(1-\alpha_{j}\right) \pi_{i}+\alpha_{i} \pi_{j}$, the sustainability constraint (7) can be solved for the critical value $\tilde{\delta}_{i}^{*}$ of the discount factor as is shown in equation (8). For individual discount factors above this threshold, collusion is a stable outcome:

$$
\delta_{i}>\frac{\left(1-\alpha_{j}\right)\left(\pi_{i, d}-\pi_{i, k}\right)+\alpha_{i}\left(\pi_{j,-d}-\pi_{j, k}\right)}{\left(1-\alpha_{j}\right)\left(\pi_{i, d}-\pi_{i, c}\right)+\alpha_{i}\left(\pi_{j,-d}-\pi_{j, c}\right)} \equiv \tilde{\delta}_{i}^{*} .
$$

Proposition 1 establishes under which condition the critical discount factor rises in the value of minority shareholdings $\alpha_{i}$ :

Proposition 1 The inequality $\partial \tilde{\delta}_{i}^{*} / \partial \alpha_{i}>0$ applies if inequality (9) is satisfied:

$$
\begin{array}{r}
\left(1-\alpha_{j}\right)\left[\left(\pi_{j, k}-\pi_{j, c}\right) \pi_{i, d}-\left(\pi_{i, k}-\pi_{i, c}\right) \pi_{j,-d}-\left(\pi_{i, c}-\pi_{j, c}\right) \pi_{i, k}\right] \\
\left(1-\alpha_{j}\right)\left(\pi_{i, d}-\pi_{i, k}\right)+\alpha_{i}\left(\pi_{j,-d}-\pi_{j, k}\right) \\
<\left(1-\alpha_{j}\right) \frac{\partial \pi_{i, c}}{\partial \alpha_{i}}+\alpha_{i} \frac{\partial \pi_{j, c}}{\partial \alpha_{i}} .
\end{array}
$$

Proof See "Appendix 2".

To interpret condition (9), higher shareholdings $\alpha_{i}$ have two effects on the sustainability of collusion:

Effect 1: Malueg (1992) argued that higher shareholdings have a destabilizing effect on collusion by increasing firms' profits in competition and, thus, reducing the grim trigger punishment $\pi_{i, c}-\pi_{i, k}$ that follows a deviation. This can be inferred from the right-hand side of (9), which captures the elevating effect of minority shareholdings on firms' profits in competition. One finds $\partial \tilde{\delta}_{i}^{*} / \partial \alpha_{i}>0$ when the right-hand side of inequality (9) is sufficiently high.

Effect 2: NCMS also have a stabilizing effect on collusion. If firm $i$ deviates, the profits of firm $j$ fall from $\pi_{j, k}$ to $\pi_{j,-d}$. This reduces the dividend that firm $j$ pays to the majority owner of firm $i$. In absolute terms, this reduction of the dividend is stronger if the majority owner of firm $i$ holds a greater share $\alpha_{i}$ in firm $j$. This makes firm $i$ more reluctant to deviate because $\alpha_{i}\left(\pi_{j,-d}-\pi_{j, k}\right)$ in the denominator of the left-hand side of (9) measures the loss of dividends that are received from firm $j$ if firm $i$ deviates. A higher value of $\alpha_{i}$ raises the left-hand side of (9) and, thus, contributes to situations with $\partial \tilde{\delta}_{i}^{*} / \partial \alpha_{i}<0$. 


\subsection{The Sustainability of Collusion in Different Models of Competition}

This subsection explores the effect of minority shareholdings on the stability of collusion by exploring the relative strength of Effect 1 and Effect 2 in different models of competition.

Cournot competition In Cournot competition, an asymmetric increase in the shareholdings $\alpha_{i}$ cannot destabilize collusion by raising $\tilde{\delta}_{i}^{*}$ (Lemma 4), yet a symmetric increase can have this destabilizing effect (Lemma 5).

Lemma 4 In Cournot competition with $\partial q_{j}^{R} / \partial q_{i}<0$, one finds that $\left(1-\alpha_{j}\right) \cdot \partial \pi_{i, c} / \partial \alpha_{i}+\alpha_{i} \cdot \partial \pi_{j, c} / \partial \alpha_{i}<0$.

Proof See "Appendix 2".

Lemma 1 established that in Cournot competition firm $i$ would want to reduce its output and, thus, soften competition if its majority shareholder acquires shares $\alpha_{i}$ of its rival $j$. Because of the strategic substitutability of quantities $\left(\partial q_{j}^{R} / \partial q_{i}<0\right)$, firm $j$ would however react by expanding its output, which leads to $\partial \pi_{i, c} / \partial \alpha_{i}<0$ and $\partial \pi_{j, c} / \partial \alpha_{i}>0$. Because firm $i$ 's majority shareholder participates more in the decline of firm $i$ 's profits than in the increasing profits of $j,\left(1-\alpha_{j}\right)>\alpha_{i}$, one finds that $\left(1-\alpha_{j}\right) \cdot \partial \pi_{i, c} / \partial \alpha_{i}+\alpha_{i} \cdot \partial \pi_{j, c} / \partial \alpha_{i}<0$. Therefore, inequality (9) would be violated, which implies $\partial \tilde{\delta}_{i}^{*} / \partial \alpha_{i}<0$.

Lemma 5 shows that this is different if the firms choose symmetric shareholdings and also if any increase in the shareholdings is symmetric: $\alpha_{i}=\alpha_{j}=\alpha \forall \alpha_{i}, \alpha_{j}$.

Lemma 5 In Cournot competition with $\partial q_{j}^{R} / \partial q_{i}<0$ and $\alpha_{i}=\alpha_{j}=\alpha \forall \alpha_{i}, \alpha_{j}$, one finds that $(1-\alpha) \partial \pi_{i, c} / \partial \alpha+\alpha \cdot \partial \pi_{j, c} / \partial \alpha>0$.

Proof See "Appendix 2".

The inequality $(1-\alpha) \partial \pi_{i, c} / \partial \alpha+\alpha \cdot \partial \pi_{j, c} / \partial \alpha>0$ for symmetric increases of the shareholdings is a prerequisite for the destabilizing effect of NCMS on collusion as was shown by Malueg (1992). If the firms raise their shares in each other symmetrically, both firms' profits $\pi_{i, c}, \pi_{j, c}$ rise. This reduces the loss that is inflicted on a firm by grim trigger punishments and contributes to raising the critical discount factor $\tilde{\delta}_{i}^{*}$.

Bertrand competition with differentiated products Collusion-destabilizing effects of NCMS $-\partial \tilde{\delta}_{i}^{*} / \partial \alpha_{i}>0$ - are more likely in Bertrand competition with differentiated products than in Cournot competition. This is because in Bertrand competition with differentiated products even asymmetric increases of $\alpha_{i}$ may raise the righthand side of inequality (9) as was shown by Lemma 3 . This finding suggests that the pro-competitive effects of NCMS are even more prevalent than was suggested by Malueg's (1992) seminal contribution.

Bertrand competition with homogeneous products NCMS do not have an impact on firms' profits under the assumption of price competition with homogeneous products: $\partial \pi_{i, c} / \partial \alpha_{i}=0, \partial \pi_{j, c} / \partial \alpha_{j}=0$. Therefore, the right-hand side of inequality (9) 
takes a value of zero, which implies $\partial \delta_{i}^{*} / \partial \alpha_{i}<0 \forall \alpha_{i}$. This result is in line with the finding of Gilo et al. (2006), who showed that under the assumption of Bertrand competition with homogeneous products "an increase in firm [i]'s stake in firm [j] never hinders tacit collusion". 4

\subsection{The Effect of $\alpha_{j}$ on $\tilde{\delta}_{i}^{*}$}

The previous analysis was concerned with the effects of the stake $\alpha_{i}$, which firm $i$ 's majority shareholder possesses in firm $j$, on $i$ 's critical discount factor $\tilde{\delta}_{i}^{*}$. Proposition 2 goes beyond the prior literature by showing under what condition the stake $\alpha_{j}$ of firm $j$ 's majority stakeholder in firm $i$ makes collusion harder to sustain by increasing firm $i$ 's critical discount factor $\tilde{\delta}_{i}^{*}$ :

Proposition 2 The inequality $\partial \tilde{\delta}_{i}^{*} / \partial \alpha_{j}>0$ applies if inequality (10) is satisfied:

$$
\begin{array}{r}
\alpha_{i}\left[\left(\pi_{j, k}-\pi_{j, c}\right) \pi_{i, d}-\left(\pi_{i, k}-\pi_{i, c}\right) \pi_{j,-d}-\left(\pi_{i, c}-\pi_{j, c}\right) \pi_{i, k}+\left(\pi_{i, k}-\pi_{j, k}\right) \pi_{i, c}\right] \\
\left(1-\alpha_{j}\right)\left(\pi_{i, d}-\pi_{i, k}\right)+\alpha_{i}\left(\pi_{j,-d}-\pi_{j, k}\right) \\
<\left(1-\alpha_{j}\right) \frac{\partial \pi_{i, c}}{\partial \alpha_{j}}+\alpha_{i} \frac{\partial \pi_{j, c}}{\partial \alpha_{j}} .
\end{array}
$$

Proof See "Appendix 2".

The inequality $\partial \tilde{\delta}_{i}^{*} / \partial \alpha_{j}>0$, which results if inequality (10) applies, is a result of firm $j$ 's incentive to soften competition after its majority shareholder acquires shares of firm $i$. This raises the profits that are made by both firms when competing, and it thus softens the grim trigger punishments, which makes it more attractive for firm $i$ to deviate.

Note that inequality (10) in Proposition 2 is easier to satisfy than inequality (9) in Proposition 1. This can be seen particularly well when starting from a situation of symmetry $\left(\alpha_{i}=\alpha_{j}\right)$ before analyzing an asymmetric expansion of $\alpha_{j}$. Symmetry causes $\pi_{i, c}-\pi_{j, c}=0, \pi_{i, k}-\pi_{j, k}=0, \partial \pi_{i, c} / \partial \alpha_{i}=\partial \pi_{j, c} / \partial \alpha_{j}$ and $\partial \pi_{j, c} / \partial \alpha_{i}=\partial \pi_{i, c} / \partial \alpha_{j}$. Together with $\alpha_{i}<1-\alpha_{j}$, these equalities can be used to show that the right-hand side of (10) is weakly greater than that of (9).

Taken together, this causes $\tilde{\delta}_{i}^{*}$ to be increased more easily by an increase in $\alpha_{j}$ than by an increase in $\alpha_{i}$. Because earlier literature focused on $\partial \tilde{\delta}_{i}^{*} / \partial \alpha_{i}$, Proposition 2 implies that a collusion-destabilizing effect of minority shareholdings occurs under a wider set of conditions than was predicted by this earlier literature.

\footnotetext{
${ }^{4}$ Note that Gilo et al. (2006) assumed that the firms maximize the profit function $\hat{\pi}_{i}=\pi_{i}+\alpha_{i} \hat{\pi}_{j}$ rather than $\tilde{\pi}_{i}=\left(1-\alpha_{j}\right) \pi_{i}+\alpha_{i} \pi_{j}$. Although these functions model different aspects of minority shareholdings - common ownership vs. cross ownership - their effect on our results is minor and has no impact on our qualitative conclusions as will be discussed in Sect. 6.
} 


\section{Competition Authority}

As a further addition to prior literature, we merge our model with that of Aubert et al. (2006) to study the effect of a competition authority on the stability of collusion in the presence of common ownership. This is modeled by assuming that the competition authority detects a collusive agreement with probability $\rho$ in every period and then imposes a fine $F$ on every colluding firm.

Proposition 3 demonstrates the main result of this section: The collusion-destabilizing effect of common ownership is further enhanced by $\rho F>0$.

Proposition 3 Given the detection probability $\rho$ and fine $F$, the critical discount factor takes the functional form shown in (11). Inequality $\partial \tilde{\delta}_{i}^{*} / \partial \alpha_{i}>0$ applies if inequality (12) is satisfied, which is easier to satisfy than the corresponding inequality (9) for $\rho F=0$ :

$$
\begin{gathered}
\tilde{\delta}_{i}^{*} \equiv \frac{\left(1-\alpha_{j}\right)\left(\pi_{i, d}-\pi_{i, k}\right)+\alpha_{i}\left(\pi_{j,-d}-\pi_{j, k}\right)}{\left(1-\alpha_{j}\right)\left(\pi_{i, d}-\rho F-\pi_{i, c}\right)+\alpha_{i}\left(\pi_{j,-d}-\rho F-\pi_{j, c}\right)} ; \\
\frac{\left(1-\alpha_{j}\right)\left[\left(\pi_{j, k}-\rho F-\pi_{j, c}\right) \pi_{i, d}-\left(\pi_{i, k}-\rho F-\pi_{i, c}\right) \pi_{j,-d}-\left(\pi_{i, c}-\pi_{j, c}\right) \pi_{i, k}\right]}{\left(1-\alpha_{j}\right)\left(\pi_{i, d}-\pi_{i, k}\right)+\alpha_{i}\left(\pi_{j,-d}-\pi_{j, k}\right)} \\
<\left(1-\alpha_{j}\right) \frac{\partial \pi_{i, c}}{\partial \alpha_{i}}+\alpha_{i} \frac{\partial \pi_{j, c}}{\partial \alpha_{i}} .
\end{gathered}
$$

Proof See "Appendix 3".

Proposition 3 suggests that $\rho F>0$ makes minority shareholdings more likely to destabilize collusion. This is because the competition authority imposes a fine not only on firm $i$ but also on firm $j$. This causes the expected dividend income of firm $i$ 's minority shareholder to be low whether the firm adheres to the collusive agreement or not, which makes a deviation relatively more profitable for firm $i$. Mathematically, $\rho F>0$ decreases the left-hand side of (12), which makes it more likely to find $\partial \tilde{\delta}_{i}^{*} / \partial \alpha_{i}>0$.

\section{Cross Ownership}

Up to this point, we have relied on profit function (1): $\tilde{\pi}_{i}=\left(1-\alpha_{j}\right) \pi_{i}+\alpha_{i} \pi_{j}$. The payoff $\tilde{\pi}_{i}$ models the income of a common shareholder who possesses a majority share $1-\alpha_{j}$ of firm $i$ and a minority share $\alpha_{i}$ of firm $j$.

A different profit function was used, for example, by Flath (1991), Gilo et al. (2006), and Shelegia and Spiegel (2012), which is shown in (13):

$$
\max \hat{\pi}_{i}=\pi_{i}+\alpha_{i} \hat{\pi}_{j}
$$


The profit $\hat{\pi}_{i}$ models firm $i$ 's profit as it appears in its income statement: its operating profit $\pi_{i}$ plus its investment income $\alpha_{i} \hat{\pi}_{j}$. This profit function is typically used when modeling the effect of cross ownership, with $\alpha_{i}$ denoting the share of firm $i$ in firm $j$. An overview about the literature that surrounds the interpretation of profit functions (1) and (13) was given by Schmalz (2018).

In "Appendix 4", we show that only the functional form but not the economic interpretation of our results changes if one instead assumes profit function (13). As above, the critical discount factor is shown to rise in $\alpha_{i}$ and (even more easily) in $\alpha_{j}$ if the NCMS raise firms' profits in competition sufficiently strongly. A high value of the expected fine facilitates these situations.

\section{Conclusion}

This article presents a framework for the analysis of collusion in the presence of common ownership or cross ownership. We combined the established models of Reynolds and Snapp (1986), Flath (1991, 1992), Malueg (1992), and Gilo et al. (2006). These earlier contributions had not always been easy to compare: First, because they used different profit functions. Second, some combinations of assumptions had so far remained unexplored. Third, they sometimes relied on numerical proofs. We fill these gaps in the literature by studying the 'missing' combinations of assumptions and thus improving the comparability of these earlier contributions. The properties of our model are proven analytically. Additionally, we extend this literature by adding a competition authority (Aubert et al. 2006) and analyzing the effect of firm $i$ 's shareholdings on the critical discount factor of firm $j$.

Malueg (1992) pointed out that NCMS raise the profits that firms make when competing, which contributes to weakening the sustainability of collusion. Our study indicates that NCMS weaken the sustainability of collusion under an even greater variety of circumstances than was acknowledged by this earlier literature.

The integrated framework that we proposed in this article establishes a basis for further theoretical extensions. For example, it will be interesting to endogenize firms' decisions to acquire NCMS. The firms might decide about splitting the collusive profits unequally or making side payments, which might be necessary if the firms were asymmetric in costs. Future work should extend our duopoly model to the case of $n$ firms and, additionally, explore the impact of other than grim trigger punishments. Several approaches have been proposed for modeling the effect of competition authorities on collusion among independent firms (see Harrington (2017) for a review), which may now also be applied to the study of collusion in the presence of common ownership or cross ownership.

Acknowledgements Open Access funding provided by Projekt DEAL. We would like to thank Lawrence J. White (the editor) and two anonymous referees for helping us to improve this article greatly. Earlier versions were discussed with great care by Iwan Bos, Carsten Crede, Georg Götz, Daniel Herold, Inés Pérez-Soba Aguilar, and Yossi Spiegel. We are also grateful for the comments provided by the participants of the MaCCI (Mannheim, 2015), CISS (Marmaris, 2015), ERSA (Cape Town, 2015), EALE (Vienna, 2015), EARIE (Lisbon, 2016), Verein für Socialplitik (Augsburg, 2016) conferences, and a seminar held at the Düsseldorf Institute for Competition Economics (2016). 
Open Access This article is licensed under a Creative Commons Attribution 4.0 International License, which permits use, sharing, adaptation, distribution and reproduction in any medium or format, as long as you give appropriate credit to the original author(s) and the source, provide a link to the Creative Commons licence, and indicate if changes were made. The images or other third party material in this article are included in the article's Creative Commons licence, unless indicated otherwise in a credit line to the material. If material is not included in the article's Creative Commons licence and your intended use is not permitted by statutory regulation or exceeds the permitted use, you will need to obtain permission directly from the copyright holder. To view a copy of this licence, visit http://creativecommons.org/licen ses/by/4.0/.

\section{Appendix to Section 3}

The following proofs assume that the firms produce subject to constant marginal costs taking a value of zero.

Proof Lemma 1 proposes $\partial \pi_{i, c} / \partial \alpha_{i}<0$ and $\partial \pi_{i, c} / \partial \alpha_{j}>0$ for Cournot competition with $\partial q_{i}^{R} / \partial q_{j}<0$ and profit function (1). To prove this, reaction function (A.3) is determined by deriving profit function (A.1) for $q_{i}$ and solving first-order condition (A.2) for $q_{i}$, while we define $q_{i}^{R}\left(q_{j}\right)=\tilde{q}_{i}^{R}\left(q_{j}, 0,0\right)$ :

$$
\begin{gathered}
\tilde{\pi}_{i}=\left(1-\alpha_{j}\right) p\left(q_{i}, q_{j}\right) q_{i}+\alpha_{i} p\left(q_{i}, q_{j}\right) q_{j} \\
\frac{\partial \tilde{\pi}_{i}}{\partial q_{i}}=\left(1-\alpha_{j}\right)\left[\frac{\partial p}{\partial q_{i}} q_{i}+p\left(q_{i}, q_{j}\right)\right]+\alpha_{i} \frac{\partial p}{\partial q_{i}} q_{j}=0 ; \\
\tilde{q}_{i}^{R}\left(q_{j}, \alpha_{i}, \alpha_{j}\right)=q_{i}^{R}\left(q_{j}\right)-\frac{\alpha_{i}}{1-\alpha_{j}} \theta q_{j} .
\end{gathered}
$$

The variable $\theta$ is a scaling factor with $0<\theta<1$. For a specific homogeneous products demand curve $p=\left(1-q_{i}-q_{j}\right)^{x}$ with $x>0$ (Malueg 1992) one finds $\theta=x /(1+x)$, and one can show that $-1<\partial q_{i}^{R} / \partial q_{j}<0$. Given $\partial q_{i}^{R} / \partial q_{j}<0$, equation (A.3) implies $\partial \tilde{q}_{i}^{R} / \partial q_{j}<0$ and, thus, $\partial \tilde{q}_{j}^{R} / \partial q_{i}<0$.

To prove $\partial \pi_{i, c} / \partial \alpha_{i}<0$, note that equation (A.3) implies $\tilde{q}_{i}^{R}\left(q_{j}, \alpha_{i}, \alpha_{j}\right)<q_{i}^{R}\left(q_{j}\right)$ for an unchanged value of $q_{j}$. Because of $\partial \tilde{q}_{j}^{R} / \partial q_{i}<0$ firm $j$ will optimally expand its output, which causes firm $i$ to contract its output even further. This implies that $\tilde{q}_{i}^{R}\left(\tilde{q}_{j}^{R}, \alpha_{i}, \alpha_{j}\right)<q_{i}^{R}\left(q_{j}^{R}\right)$ and $\tilde{q}_{j}^{R}\left(\tilde{q}_{i}^{R}, \alpha_{j}, \alpha_{i}\right)>q_{j}^{R}\left(q_{i}^{R}\right), \partial \tilde{q}_{i}^{R} / \partial \alpha_{i}<0$ and $\partial \tilde{q}_{j}^{R} / \partial \alpha_{i}>0$. Firm $i$ 's product market profit is reduced by selling a lower than the optimal quantity $\tilde{q}_{i}^{R}<q_{i}^{R}$ while firm $j$ raises its output, which implies and proves $\partial \pi_{i, c} / \partial \alpha_{i}<0$.

Because the output reduction of firm $i$ exceeds the output expansion of firm $j$ the equilibrium price rises: From $-1<\partial \tilde{q}_{j}^{R} / \partial q_{i}$ it follows that $\partial \tilde{q}_{j}^{R} / \partial \alpha_{i}=\left(\partial \tilde{q}_{j}^{R} / \partial q_{i}\right) \cdot\left(\partial \tilde{q}_{i}^{R} / \partial \alpha_{i}\right)<-\partial \tilde{q}_{i}^{R} / \partial \alpha_{i}$, such that $\partial\left(\tilde{q}_{i}^{R}+\tilde{q}_{j}^{R}\right) / \partial \alpha_{i}<0$ and $\partial p\left(\tilde{q}_{i}^{R}+\tilde{q}_{j}^{R}\right) / \partial \alpha_{i}>0$. Combining $\partial p\left(\tilde{q}_{i}^{R}+\tilde{q}_{j}^{R}\right) / \partial \alpha_{i}>0$ and $\partial \tilde{q}_{j}^{R} / \partial \alpha_{i}>0$ proves that $\partial \pi_{j, c} / \partial \alpha_{i}>0$ for Cournot competition and profit function (1). 
Proof Lemma 2 proposes for Cournot competition that $\partial \pi_{i, d} / \partial \alpha_{i}<0$ and $\partial \pi_{j,-d} / \partial \alpha_{i}>0$. Firm $j$ keeps its output $q_{j,-d}=q_{j, k}$ constant by assumption: $\partial q_{j,-d} / \partial \alpha_{i}=0$. Reaction function (A.3) with $\partial \tilde{q}_{i}^{R}\left(q_{j,-d}, \alpha_{i}, \alpha_{j}\right) / \partial \alpha_{i}<0$ causes $\partial\left(q_{j,-d}+\tilde{q}_{i}^{R}\left(q_{j,-d}, \alpha_{i}, \alpha_{j}\right)\right) / \partial \alpha_{i}<0$ and thus $\partial p_{d} / \partial \alpha_{i}>0$. This proves that $\partial \pi_{j,-d} / \partial \alpha_{i}=\left(\partial p_{d} / \partial \alpha_{i}\right) \cdot q_{j,-d}>0$. Inequality $\partial \tilde{q}_{i}^{R}\left(q_{j,-d}, \alpha_{i}, \alpha_{j}\right) / \partial \alpha_{i}<0 \quad$ also implies that with $\alpha_{i}>0$ firm $i$ sets a lower output as in a case with $\alpha_{i}, \alpha_{j}=0$, i.e., $\tilde{q}_{i}^{R}\left(q_{j,-d}, \alpha_{i}, \alpha_{j}\right)<q_{i}^{R}\left(q_{j,-d}\right)$, which causes $\pi_{i}\left(\tilde{q}_{i}^{R}, q_{j,-d}\right)<\pi_{i}\left(q_{i}^{R}, q_{j,-d}\right)$. This proves $\partial \pi_{i, d} / \partial \alpha_{i}<0$.

Proof Lemma 3 proposes for Bertrand competition with differentiated products that $\partial \pi_{i, c} / \partial \alpha_{i}>0$ if $\alpha_{i}<\alpha_{j}+A, \partial \pi_{i, c} / \partial \alpha_{i} \leq 0$ if $\alpha_{i} \geq \alpha_{j}+A$, and $\partial \pi_{i, c} / \partial \alpha_{j}>0$. The term $\tilde{p}_{i}^{R}\left(p_{j}, \alpha_{i}, \alpha_{j}\right)$ in equation (A.6) denotes the reaction function of firm $i$, and it is determined by maximizing profit function (A.4) with respect to $p_{i}$. Equation (A.5) presents the first-order condition. The term $p_{i}^{R}\left(p_{j}\right)$ in (A.6) denotes the reaction function if firm $i$ maximizes its own product market profits $\pi_{i}$ only, i.e., $p_{i}^{R}\left(p_{j}\right)=\tilde{p}_{i}^{R}\left(p_{j}, 0,0\right)$ :

$$
\begin{gathered}
\tilde{\pi}_{i}=\left(1-\alpha_{j}\right) q_{i}\left(p_{i}, p_{j}\right) p_{i}+\alpha_{i} q_{j}\left(p_{j}, p_{i}\right) p_{j} \\
\frac{\partial \tilde{\pi}_{i}}{\partial p_{i}}=\left(1-\alpha_{j}\right)\left[\frac{\partial q_{i}}{\partial p_{i}} p_{i}+q_{i}\left(p_{i}, p_{j}\right)\right]+\alpha_{i} \frac{\partial q_{j}}{\partial p_{i}} p_{j}=0 \\
\tilde{p}_{i}^{R}\left(p_{j}, \alpha_{i}, \alpha_{j}\right)=p_{i}^{R}\left(p_{j}\right)+\frac{\alpha_{i}}{1-\alpha_{j}} B p_{j}
\end{gathered}
$$

For a specific demand function such as $q_{i}=1-p_{i}+\beta p_{j}$ with $0<\beta<1$, one can prove that $0<\partial p_{i}^{R} / \partial p_{j}<1$, and one finds that $B=\beta / 2>0$. Equation (A.6) indicates that $\partial \tilde{p}_{i}^{R} / \partial \alpha_{i}>0$ for a given value of $p_{j}$. Moreover, firm $i$ will increase its price if firm $j$ acquires shares of firm $i$, i.e., $\partial \tilde{p}_{i}^{R} / \partial \alpha_{j}$, which can be written as in (A.7):

$$
\frac{\partial \tilde{p}_{i}^{R}\left(\tilde{p}_{j}^{R}, \alpha_{i}, \alpha_{j}\right)}{\partial \alpha_{j}}=\frac{\partial p_{i}^{R}}{\partial p_{j}} \cdot \frac{\partial \tilde{p}_{j}^{R}}{\partial \alpha_{j}}+\frac{\alpha_{i} B p_{j}}{\left(1-\alpha_{j}\right)^{2}}+\frac{\alpha_{i} B}{1-\alpha_{j}} \cdot \frac{\partial \tilde{p}_{j}^{R}}{\partial \alpha_{j}} .
$$

Given (A.7), $\partial p_{i}^{R} / \partial p_{j}>0$, and $\partial \tilde{p}_{j}^{R} / \partial \alpha_{j}>0$, one finds that $\partial \tilde{p}_{i}^{R} / \partial \alpha_{j}>0$ and, accordingly, $\partial \tilde{p}_{j}^{R} / \partial \alpha_{i}>0$. For $q_{i}=1-p_{i}+\beta p_{j}$ one can show that $\partial \tilde{p}_{j}^{R} / \partial \alpha_{i}<\partial \tilde{p}_{i}^{R} / \partial \alpha_{i}$ and $\partial q_{i}\left(\tilde{p}_{i}^{R}, \tilde{p}_{j}^{R}\right) / \partial \alpha_{i}<0$ apply. Because of $\partial \tilde{p}_{j}^{R} / \partial \alpha_{j}>0$ after firm $j$ acquires shares $\alpha_{j}$ of firm $i$, the output and profit of firm $i$ would rise even when holding its own price constant. Firm $i$ will only raise its price $\left(\partial \tilde{p}_{j}^{R} / \partial p_{j}>0\right)$ if this raises its profit even further, which proves $\partial \pi_{i, c} / \partial \alpha_{j}>0$.

Yet, the inequalities $\partial \tilde{p}_{i}^{R} / \partial \alpha_{i}>0$ and $\partial q_{i}\left(\tilde{p}_{i}^{R}, \tilde{p}_{j}^{R}\right) / \partial \alpha_{i}<0$ suggest an ambiguous effect on the profits of firm $i \quad\left(\partial \pi_{i, c} / \partial \alpha_{i} \lesseqgtr 0\right)$. For proving that $\partial \pi_{i, c} / \partial \alpha_{i}>0$ if $\alpha_{i}<\alpha_{j}+A$, one has to assume a specific functional form for 
demand: We use $q_{i}=1-p_{i}+\beta p_{j}{ }^{5}$. The price and profit of firm $i$ in the product market-equilibrium are then shown in (A.8) and (A.9):

$$
\begin{gathered}
\tilde{p}_{i}^{R}\left(\tilde{p}_{j}^{R}, \alpha_{i}, \alpha_{j}\right)=\frac{2+\left(\frac{1+\left(\alpha_{i}-\alpha_{j}\right)}{1-\alpha_{j}}\right) \beta}{4-\left(\frac{1+\left(\alpha_{i}-\alpha_{j}\right)}{1-\alpha_{j}}\right) \beta^{2}\left(\frac{1-\left(\alpha_{i}-\alpha_{j}\right)}{1-\alpha_{i}}\right)} ; \\
\pi_{i, c}=\pi_{i}\left(\tilde{p}_{i}^{R}, \tilde{p}_{j}^{R}\right)=q_{i}\left(\tilde{p}_{i}^{R}, \tilde{p}_{j}^{R}\right) \tilde{p}_{i}^{R}=\left(1-\tilde{p}_{i}^{R}+\beta \tilde{p}_{j}^{R}\right) \tilde{p}_{i}^{R} .
\end{gathered}
$$

Ideally, one would want to plug $\tilde{p}_{i}^{R}$ and $\tilde{p}_{j}^{R}$ into (A.9), determine $\partial \pi_{i, c} / \partial \alpha_{i}$ and solve inequality $\partial \pi_{i, c} / \partial \alpha_{i}>0$ for $\alpha_{i}$, which would yield a term $\alpha_{i}<\alpha_{j}+A$. Yet, the threshold $A$ proves to be a highly nonlinear and lengthy function of $\alpha_{j}$ and $\beta$.

We thus resort to a more subtle proof: The condition $\partial \pi_{i, c} / \partial \alpha_{i}>0$ can be stated as in (A.10).

$$
\begin{aligned}
& \frac{\partial \pi_{i, c}}{\partial \alpha_{i}}=\left(-\frac{\partial \tilde{p}_{i}^{R}}{\partial \alpha_{i}}+\beta \frac{\partial \tilde{p}_{j}^{R}}{\partial \alpha_{i}}\right) \tilde{p}_{i}^{R}+\left(1-\tilde{p}_{i}^{R}+\beta \tilde{p}_{j}^{R}\right) \frac{\partial \tilde{p}_{i}^{R}}{\partial \alpha_{i}}>0 \\
& \frac{1+\beta \tilde{p}_{j}^{R}}{2-\left(\frac{\partial \tilde{p}_{j}^{R} / \partial \alpha_{i}}{\partial \tilde{p}_{i}^{R} / \partial \alpha_{i}}\right) \beta} \quad>\tilde{p}_{i}^{R}
\end{aligned}
$$

When holding $\alpha_{j}$ constant, a unilateral increase in $\alpha_{i}$ increases $\pi_{i, c}$ as long as $\tilde{p}_{i}^{R}$ is smaller than the left-hand side of (A.10). Because of $\partial \tilde{p}_{i}^{R} / \partial \alpha_{i}>\partial \tilde{p}_{j}^{R} / \partial \alpha_{i}$ an increase in $\alpha_{i}$ increases $\tilde{p}_{i}^{R}$ more strongly than the left-hand side of (A.10), so that $\partial \pi_{i, c} / \partial \alpha_{i} \leq 0$ will apply once reaching or exceeding the tipping point $\alpha_{i} \geq \alpha_{j}+A$. It can be seen that $\partial \pi_{i, c} / \partial \alpha_{i}>0$ is a consequence of the strategic complementarity of prices: Inequality (A.10) is more easily satisfied for higher values of both $\partial \tilde{p}_{j}^{R} / \partial \alpha_{i}$ and $\beta$.

Proof Lemma 2 proposes for Bertrand competition with differentiated products $\partial \pi_{i, d} / \partial \alpha_{i}<0$ and $\partial \pi_{j,-d} / \partial \alpha_{i}>0$. The assumption $p_{j,-d}=p_{j, k}$ implies $\partial p_{j,-d} / \partial \alpha_{i}=0$. Reaction function (A.6) causes a higher deviation price $\left(\partial \tilde{p}_{i}^{R}\left(p_{j,-d}, \alpha_{i}, \alpha_{j}\right) / \partial \alpha_{i}>0\right)$ in the presence of minority shareholdings and thus less business stealing $\left(\partial q_{j,-d} / \partial \alpha_{i}>0\right)$. This proves $\partial \pi_{j,-d} / \partial \alpha_{i}=\left(\partial q_{j,-d} / \partial \alpha_{i}\right) \cdot p_{j,-d}>0$. Finding $\partial \tilde{p}_{i}^{R}\left(p_{j,-d}, \alpha_{i}, \alpha_{j}\right) / \partial \alpha_{i}>0$ also implies that with $\alpha_{i}>0$ firm $i$ sets a higher than the profit-maximizing price $p_{i}^{R}\left(p_{j,-d}\right)<\tilde{p}_{i}^{R}\left(p_{j,-d}, \alpha_{i}, \alpha_{j}\right)$, which causes $\pi_{i}\left(p_{i}^{R}, p_{j,-d}\right)>\pi_{i}\left(\tilde{p}_{i}^{R}, p_{j,-d}\right)$. This proves $\partial \pi_{i, d} / \partial \alpha_{i}<0$.

\footnotetext{
${ }^{5}$ Flath (1991) provides proofs for a Hotelling model. A Salop circle model with three firms and asymmetric, controlling shareholdings was provided by Øystein et al. (2011). Yet, these proofs were done under the assumption of profit function (13).
} 


\section{Appendix to Section 4}

The proof of Proposition 1 relies on Lemma 6:

Lemma $6\left(1-\alpha_{j}\right) \frac{\partial \pi_{i, d}}{\partial \alpha_{i}}+\alpha_{i} \frac{\partial \pi_{j,-d}}{\partial \alpha_{i}}=0$.

Proof For Cournot competition with homogeneous products, the equality stated in Lemma 6 can be restated as in (B.1):

$$
\left(1-\alpha_{j}\right) \frac{\partial \pi_{i, d}}{\partial \alpha_{i}}+\alpha_{i} \frac{\partial \pi_{j,-d}}{\partial \alpha_{i}}=\frac{\partial q_{i}}{\partial \alpha_{i}}\left[\left(1-\alpha_{j}\right)\left(\frac{\partial p}{\partial q_{i}} q_{i}+p\right)+\alpha_{i} \frac{\partial p}{\partial q_{i}} q_{j}\right] .
$$

The bracketed term on the right-hand side of equation (B.1) is the same as the bracketed term in first-order condition (A.2) that takes a value of zero in the optimum. For Bertrand competition with differentiated products, the equality stated in Lemma 6 can be restated as in (B.2):

$$
\left(1-\alpha_{j}\right) \frac{\partial \pi_{i, d}}{\partial \alpha_{i}}+\alpha_{i} \frac{\partial \pi_{j,-d}}{\partial \alpha_{i}}=\frac{\partial p_{i}^{R}}{\partial \alpha_{i}}\left[\left(1-\alpha_{j}\right)\left(\frac{\partial q_{i}}{\partial p_{i}} p_{i}+q_{i}\right)+\alpha_{i}\left(\frac{\partial q_{j}}{\partial p_{i}} q_{j}\right)\right]=0 .
$$

The bracketed term on the right-hand side of equation (B.2) is the same as the bracketed term in first-order condition (A.5) that takes a value of zero in the optimum. Section 3.2 established that $\partial \pi_{i, d} / \partial \alpha_{i}=0$ and $\partial \pi_{j,-d} / \partial \alpha_{i}=0$ for Bertrand competition with homogeneous products, which proves $\left(1-\alpha_{j}\right)\left(\partial \pi_{i, d} / \partial \alpha_{i}\right)+\alpha_{i}\left(\partial \pi_{j,-d} / \partial \alpha_{i}\right)=0$.

Proof To determine $\partial \tilde{\delta}_{i}^{*} / \partial \alpha_{i}>0$ (Proposition 1), re-write $\tilde{\delta}_{i}^{*}$ as follows:

$$
\begin{aligned}
\tilde{\delta}_{i}^{*} & =\frac{u\left(\alpha_{i}, \alpha_{j}\right)}{v\left(\alpha_{i}, \alpha_{j}\right)} \\
\text { with } u\left(\alpha_{i}, \alpha_{j}\right) & =\left(1-\alpha_{j}\right)\left(\pi_{i, d}-\pi_{i, k}\right)+\alpha_{i}\left(\pi_{j,-d}-\pi_{j, k}\right)>0 \\
\text { and } v\left(\alpha_{i}, \alpha_{j}\right) & =\left(1-\alpha_{j}\right)\left(\pi_{i, d}-\pi_{i, c}\right)+\alpha_{i}\left(\pi_{j,-d}-\pi_{j, c}\right)>0 .
\end{aligned}
$$

If we use $\partial \pi_{i, k} / \partial \alpha_{i}=\partial \pi_{j, k} / \partial \alpha_{i}=0$ and $\left(1-\alpha_{j}\right)\left(\partial \pi_{i, d} / \partial \alpha_{i}\right)+\alpha_{i}\left(\partial \pi_{j,-d} / \partial \alpha_{i}\right)=0$ from Lemma $6, \partial \tilde{\delta}_{i}^{*} / \partial \alpha_{i}$ can be written as in (B.4):

$$
\begin{gathered}
\frac{\partial \tilde{\delta}_{i}^{*}}{\partial \alpha_{i}}=\frac{\frac{\partial u\left(\alpha_{i}, \alpha_{j}\right)}{\partial \alpha_{i}} \cdot v\left(\alpha_{i}, \alpha_{j}\right)-\frac{\partial v\left(\alpha_{i}, \alpha_{j}\right)}{\partial \alpha_{i}} \cdot u\left(\alpha_{i}\right)}{v\left(\alpha_{i}, \alpha_{j}\right)^{2}} \\
\text { with } \frac{\partial u\left(\alpha_{i}, \alpha_{j}\right)}{\partial \alpha_{i}}=\pi_{j,-d}-\pi_{j, k} \\
\text { and } \frac{\partial v\left(\alpha_{i}, \alpha_{j}\right)}{\partial \alpha_{i}}
\end{gathered}
$$


Given $v\left(\alpha_{i}, \alpha_{j}\right)>0$ the sign of $\partial \tilde{\delta}^{*} / \partial \alpha_{i}$ is the same as that of its numerator as is shown in (B.5):

$$
\begin{aligned}
& \frac{\partial u\left(\alpha_{i}, \alpha_{j}\right)}{\partial \alpha_{i}} \cdot v\left(\alpha_{i}, \alpha_{j}\right)-\frac{\partial v\left(\alpha_{i}, \alpha_{j}\right)}{\partial \alpha_{i}} \cdot u\left(\alpha_{i}, \alpha_{j}\right)=\ldots \\
& \left(1-\alpha_{j}\right)\left[\left(\pi_{i, k}-\pi_{i, c}\right) \pi_{j,-d}-\left(\pi_{j, k}-\pi_{j, c}\right) \pi_{i, d}-\left(\pi_{i, c}-\pi_{j, c}\right) \pi_{i, k}\right] \\
& +\left(\left(1-\alpha_{j}\right) \frac{\partial \pi_{i, c}}{\partial \alpha_{i}}+\alpha_{i} \frac{\partial \pi_{j, c}}{\partial \alpha_{i}}\right) u\left(\alpha_{i}, \alpha_{j}\right) .
\end{aligned}
$$

Equation (B.5), and thus $\partial \tilde{\delta}^{*} / \partial \alpha_{i}$, is positive if inequality (9) applies. This proves Proposition 1.

The proof of Proposition 2 relies on Lemma 7:

Lemma $7\left(1-\alpha_{j}\right) \frac{\partial \pi_{i, d}}{\partial \alpha_{j}}+\alpha_{i} \frac{\partial \pi_{j,-d}}{\partial \alpha_{j}}=0$.

Proof For Cournot competition with homogeneous products, the equality stated in Lemma 7 can be restated as in (B.6):

$$
\left(1-\alpha_{j}\right) \frac{\partial \pi_{i, d}}{\partial \alpha_{j}}+\alpha_{i} \frac{\partial \pi_{j,-d}}{\partial \alpha_{j}}=\frac{\partial q_{i}}{\partial \alpha_{j}}\left[\left(1-\alpha_{j}\right)\left(\frac{\partial p}{\partial q_{i}} q_{i}+p\right)+\alpha_{i}\left(\frac{\partial p}{\partial q_{i}} q_{j}\right)\right]=0 .
$$

The bracketed term on the right-hand side of equation (B.6) is the same as the bracketed term in first-order condition (A.2) that takes a value of zero in the optimum. For Bertrand competition with differentiated products, the equality that is stated in Lemma 7 can be restated as in (B.7):

$$
\left(1-\alpha_{j}\right) \frac{\partial \pi_{i, d}}{\partial \alpha_{j}}+\alpha_{i} \frac{\partial \pi_{j,-d}}{\partial \alpha_{j}}=\frac{\partial p_{i}}{\partial \alpha_{j}}\left[\left(1-\alpha_{j}\right)\left(\frac{\partial q_{i}}{\partial p_{i}} p_{i}+q_{i}\right)+\alpha_{i}\left(\frac{\partial q_{j}}{\partial p_{i}} q_{j}\right)\right]=0
$$

The bracketed term on the right-hand side of equation (B.7) is the same as the bracketed term in first-order condition (A.5) that takes a value of zero in the optimum. Section 3.2 established that $\partial \pi_{i, d} / \partial \alpha_{j}=0$ and $\partial \pi_{j,-d} / \partial \alpha_{j}=0$ for Bertrand competition with homogeneous products, which proves $\left(1-\alpha_{j}\right)\left(\partial \pi_{i, d} / \partial \alpha_{j}\right)+\alpha_{i}\left(\partial \pi_{j,-d} / \partial \alpha_{j}\right)=0$.

Proof Lemma 4 proposes $\left(1-\alpha_{j}\right) \partial \pi_{i, c} / \partial \alpha_{i}+\alpha_{i} \cdot \partial \pi_{j, c} / \partial \alpha_{i}<0$ in Cournot competition with $\partial q_{j}^{R} / \partial q_{i}<0$. Given $\pi_{i}=p \cdot q_{i}$ the first derivative $\partial \pi_{i, c} / \partial \alpha_{i}$ can be written as in (B.8) if firm $i$ chooses its output $\tilde{q}_{i}^{R}$ according to the best response function (A.3). The first derivative $\partial p / \partial \alpha_{i}$ can be written as in (B.9) if one considers $Q=q_{i}+q_{j}$ and $\partial p / \partial Q=\partial p / \partial q_{i}$ because of $\partial Q / \partial q_{i}=1$. Similarly, the derivative $\partial \pi_{j, c} / \partial \alpha_{i}$ of $\pi_{j}=p \cdot q_{j}$ is shown in (B.10): 


$$
\begin{gathered}
\frac{\partial \pi_{i, c}}{\partial \alpha_{i}}=\frac{\partial p}{\partial \alpha_{i}} q_{i}+\frac{\partial \tilde{q}_{i}^{R}}{\partial \alpha_{i}} p=\frac{\partial \tilde{q}_{i}^{R}}{\partial \alpha_{i}}\left[\frac{\partial p}{\partial q_{i}}\left(1+\frac{\partial q_{j}}{\partial q_{i}}\right) q_{i}+p\right] \\
\frac{\partial p}{\partial \alpha_{i}}=\frac{\partial p}{\partial Q} \frac{\partial Q}{\partial \alpha_{i}}=\frac{\partial p}{\partial q_{i}}\left[\frac{\partial \tilde{q}_{i}^{R}}{\partial \alpha_{i}}+\frac{\partial q_{j}}{\partial \tilde{q}_{i}^{R}} \frac{\partial \tilde{q}_{i}^{R}}{\partial \alpha_{i}}\right] \\
\frac{\partial \pi_{j, c}}{\partial \alpha_{i}}=\frac{\partial p}{\partial \alpha_{i}} q_{j}+\frac{\partial q_{j}}{\partial \alpha_{i}} p=\frac{\partial \tilde{q}_{i}^{R}}{\partial \alpha_{i}}\left[\frac{\partial p}{\partial q_{i}}\left(1+\frac{\partial q_{j}}{\partial q_{i}}\right) q_{j}+\frac{\partial q_{j}}{\partial q_{i}} p\right] .
\end{gathered}
$$

Using (B.8) and (B.10), the term $\left(1-\alpha_{j}\right) \partial \pi_{i, c} / \partial \alpha_{i}+\alpha_{i} \cdot \partial \pi_{j, c} / \partial \alpha_{i}<0$ can be expressed as in (B.11):

$$
\begin{aligned}
& \left(1-\alpha_{j}\right) \frac{\partial \pi_{i, c}}{\partial \alpha_{i}}+\alpha_{i} \frac{\partial \pi_{j, c}}{\partial \alpha_{i}}=\ldots \\
& \frac{\partial \tilde{q}_{i}^{R}}{\partial \alpha_{i}}\left[\left[\left(1-\alpha_{j}\right)\left(\frac{\partial p}{\partial q_{i}} q_{i}+p\right)+\alpha_{i} \frac{\partial p}{\partial q_{i}} q_{j}\right]\left(1+\frac{\partial q_{j}}{\partial q_{i}}\right)+\frac{\partial q_{j}}{\partial q_{i}} p\left(\alpha_{i}+\alpha_{j}-1\right)\right] .
\end{aligned}
$$

The term $\left(1-\alpha_{j}\right)\left(\partial p / \partial q_{i} \cdot q_{i}+p\right)+\alpha_{i} \cdot \partial p / \partial q_{i} \cdot q_{j}$ takes a value of zero as follows from first-order condition (A.2). Lemma 1 showed that $\partial \hat{q}_{i}^{R} / \partial \alpha_{i}<0$. Combining this with $\partial q_{j} / \partial \tilde{q}_{i}^{R}<0$ and $\alpha_{i}+\alpha_{j}-1<0$, one finds $\partial \pi_{i, c} / \partial \alpha_{i}+\alpha_{i} \cdot \partial \pi_{j, c} / \partial \alpha_{i}<0$, which proves Lemma 4.

Proof With $\alpha_{i}=\alpha_{j}=\alpha$ the firms receive $\pi_{i, c}=\pi_{j, c}$, so that proving that $(1-\alpha) \cdot \partial \pi_{i, c} / \partial \alpha+\alpha \cdot \partial \pi_{j, c} / \partial \alpha>11$ (Lemma 5) requires that $\partial \pi_{i, c} / \partial \alpha>0$. This inequality is shown in (B.12) where we made use of (B.13), which requires $Q=q_{i}+q_{j}, \partial p / \partial Q=\partial p / \partial q_{i}$, and $\partial q_{i} / \partial \alpha=\partial q_{j} / \partial \alpha$ because of symmetry $\left(q_{i}=q_{j}\right)$ :

$$
\begin{gathered}
\frac{\partial \pi_{i, c}}{\partial \alpha}=\frac{\partial p}{\partial \alpha} q_{i}+\frac{\partial \tilde{q}_{i}^{R}}{\partial \alpha} p=\frac{\partial \tilde{q}_{i}^{R}}{\partial \alpha}\left[2 \frac{\partial p}{\partial q_{i}} q_{i}+p\right] \\
\frac{\partial p}{\partial \alpha}=\frac{\partial p}{\partial Q} \frac{\partial Q}{\partial \alpha}=\frac{\partial p}{\partial q_{i}}\left[\frac{\partial q_{i}}{\partial \alpha}+\frac{\partial q_{j}}{\partial \alpha}\right]=2 \frac{\partial q_{i}}{\partial \alpha} \frac{\partial p}{\partial q_{i}} .
\end{gathered}
$$

Under symmetry, first-order condition (A.2) simplifies to the first line in (B.14):

$$
\begin{aligned}
& \frac{\partial p}{\partial q_{i}} q_{i}+(1-\alpha) p=0 \\
& \frac{1}{1-\alpha} \frac{\partial p}{\partial q_{i}} q_{i}+p=0 .
\end{aligned}
$$

Given $\partial p / \partial q_{i}<0$ and $1 /(1-\alpha)<2$, this causes (B.15) where the term on the lefthand side was taken from (B.12): 


$$
2 \frac{\partial p}{\partial q_{i}} q_{i}+p<\frac{1}{1-\alpha} \frac{\partial p}{\partial q_{i}} q_{i}+p=0
$$

Combining inequality (B.15) with $\partial \tilde{q}_{i}^{R} / \partial \alpha<0$ from Lemma 1 yields $\partial \pi_{i, c} / \partial \alpha>0$, which proves Lemma 5.

Proof Proposition 2 suggests that $\partial \tilde{\delta}_{i}^{*} / \partial \alpha_{j}>0$ if inequality (10) is met. Equation (B.16) provides that $\partial \tilde{\delta}_{i}^{*} / \partial \alpha_{j}$, where the expressions for $u\left(\alpha_{i}, \alpha_{j}\right)$ and $v\left(\alpha_{i}, \alpha_{j}\right)$ are the ones given in (B.3):

$$
\begin{gathered}
\frac{\partial \tilde{\delta}_{i}^{*}}{\partial \alpha_{j}}=\frac{\frac{\partial u\left(\alpha_{i}, \alpha_{j}\right)}{\partial \alpha_{j}} \cdot v\left(\alpha_{i}, \alpha_{j}\right)-\frac{\partial v\left(\alpha_{i}, \alpha_{j}\right)}{\partial \alpha_{j}} \cdot u\left(\alpha_{i}, \alpha_{j}\right)}{v\left(\alpha_{i}, \alpha_{j}\right)^{2}} \\
\text { with } \frac{\partial u\left(\alpha_{i}, \alpha_{j}\right)}{\partial \alpha_{j}}=\pi_{i, k}-\pi_{i, d}+\left(1-\alpha_{j}\right)\left(\frac{\partial \pi_{i, d}}{\partial \alpha_{j}}-\frac{\partial \pi_{i, k}}{\partial \alpha_{j}}\right)+\alpha_{i}\left(\frac{\partial \pi_{j,-d}}{\partial \alpha_{j}}-\frac{\partial \pi_{j, k}}{\partial \alpha_{j}}\right) \\
\text { and } \frac{\partial v\left(\alpha_{i}, \alpha_{j}\right)}{\partial \alpha_{j}}=\pi_{i, c}-\pi_{i, d}+\left(1-\alpha_{j}\right)\left(\frac{\partial \pi_{i, d}}{\partial \alpha_{j}}-\frac{\partial \pi_{i, c}}{\partial \alpha_{j}}\right)+\alpha_{i}\left(\frac{\partial \pi_{j,-d}}{\partial \alpha_{j}}-\frac{\partial \pi_{j, c}}{\partial \alpha_{j}}\right) .
\end{gathered}
$$

Using $\partial \pi_{i, k} / \partial \alpha_{j}=\partial \pi_{j, k} / \partial \alpha_{j}=0$ and $\left(1-\alpha_{j}\right)\left(\partial \pi_{i, d} / \partial \alpha_{j}\right)+\alpha_{i}\left(\partial \pi_{j,-d} / \partial \alpha_{j}\right)=0$ from Lemma 7, the partial derivatives can be simplified as is shown in (B.17):

$$
\begin{aligned}
& \frac{\partial u\left(\alpha_{i}, \alpha_{j}\right)}{\partial \alpha_{j}}=\pi_{i, k}-\pi_{i, d} \\
& \frac{\partial v\left(\alpha_{i}, \alpha_{j}\right)}{\partial \alpha_{j}}=\pi_{i, c}-\pi_{i, d}-\left(1-\alpha_{j}\right) \frac{\partial \pi_{i, c}}{\partial \alpha_{j}}-\alpha_{i} \frac{\partial \pi_{j, c}}{\partial \alpha_{j}} .
\end{aligned}
$$

Equation (B.16) can thus be simplified as is shown in equation (B.18):

$$
\frac{\partial \tilde{\delta}_{i}^{*}}{\partial \alpha_{j}}=\frac{\left(\pi_{i, k}-\pi_{i, d}\right) \cdot v\left(\alpha_{i}, \alpha_{j}\right)+\left(\pi_{i, c}-\pi_{i, d}-\left(1-\alpha_{j}\right) \frac{\partial \pi_{i, c}}{\partial \alpha_{j}}-\alpha_{i} \frac{\partial \pi_{j, c}}{\partial \alpha_{j}}\right) \cdot u\left(\alpha_{i}, \alpha_{j}\right)}{v\left(\alpha_{i}, \alpha_{j}\right)^{2}} .
$$

Condition $\partial \tilde{\delta}_{i}^{*} / \partial \alpha_{j}>0$ can be solved to yield (10), which proves Proposition 2.

\section{Appendix to Section 5}

Proof Proposition 3 suggests that $\partial \tilde{\delta}_{i}^{*} / \partial \alpha_{i}>0$ if inequality (12) is satisfied. Given the detection probability $\rho$ and fine $F$, firm $i$ 's profits can be written as in (C.1) when colluding and as in (C.2) when deviating:

$$
\tilde{\pi}_{i, k}=\left(1-\alpha_{j}\right)\left(\pi_{i, k}-\rho F\right)+\alpha_{i}\left(\pi_{j, k}-\rho F\right) ;
$$




$$
\tilde{\pi}_{i, d}=\left(1-\alpha_{j}\right)\left(\pi_{i, d}-\rho F\right)+\alpha_{i}\left(\pi_{j,-d}-\rho F\right) .
$$

Plugging (C.1) and (C.2) in (7) and solving for $\delta_{i}$ yields the critical discount factor that is shown in (11). Performing the same calculations done for the proof of Proposition 1 yields inequality (12). It is straightforward to show that the left-hand side of (9) is bigger than the left-hand side of (12), which proves that (12) is easier to satisfy than (9).

\section{Appendix to Section 6}

This section demonstrates that only the functional form but not the economic interpretation of our results changes if one assumes profit function (13) for cross ownership. In this case, the competitive, collusive, and deviations profits can be stated as in (D.1)-(D.3):

$$
\begin{gathered}
\hat{\pi}_{i, c}=\frac{\pi_{i, c}+\alpha_{i} \pi_{j, c}}{1-\alpha_{i} \alpha_{j}} ; \\
\hat{\pi}_{i, k}=\frac{\left(\pi_{i, k}-\rho F\right)+\alpha_{i}\left(\pi_{j, k}-\rho F\right)}{1-\alpha_{i} \alpha_{j}} ; \\
\hat{\pi}_{i, d}=\frac{\left(\pi_{i, d}-\rho F\right)+\alpha_{i}\left(\pi_{j,-d}-\rho F\right)}{1-\alpha_{i} \alpha_{j}} .
\end{gathered}
$$

Lemmas 1-3 were established for profit function (13) by Flath (1991), Flath (1992), and Farrell and Shapiro (1990). We do not repeat these proofs because they resemble the ones that were presented in "Appendix 1".

The analysis of $\partial \hat{\delta}_{i}^{*} / \partial \alpha_{i}$ relies on condition (D.4), which we will show to apply in Cournot competition, in Bertrand competition with differentiated products, and in Bertrand competition with homogeneous products:

$$
\frac{\partial \pi_{i, d}}{\partial \alpha_{i}}+\alpha_{i} \frac{\partial \pi_{j,-d}}{\partial \alpha_{i}}=0 .
$$

In Cournot competition with homogeneous products, the profits of firm $i$ can be written as in (D.5), and its first-order condition as in (D.6). Note that the profit (D.5) is expressed before the eventual payment of $\rho F$, which constitutes a fixed cost and thus does not affect firm $i$ 's choice of its strategic variable. Equality (D.4) can be restated as in (D.7):

$$
\hat{\pi}_{i}=\frac{1}{1-\alpha_{i} \alpha_{j}}\left[p\left(q_{i}, q_{j}\right) q_{i}+\alpha_{i} p\left(q_{i}, q_{j}\right) q_{j}\right] ;
$$




$$
\begin{gathered}
\frac{\partial \hat{\pi}_{i}}{\partial q_{i}}=\frac{1}{1-\alpha_{i} \alpha_{j}}\left[\frac{\partial p}{\partial q_{i}} q_{i}+p\left(q_{i}, q_{j}\right)+\alpha_{i} \frac{\partial p}{\partial q_{i}} q_{j}\right]=0 \\
\frac{\partial \pi_{i, d}}{\partial \alpha_{i}}+\alpha_{i} \frac{\partial \pi_{j,-d}}{\partial \alpha_{i}}=\frac{\partial q_{i}^{R}}{\partial \alpha_{i}}\left[\left(\frac{\partial p}{\partial q_{i}} q_{i}+p\right)+\alpha_{i}\left(\frac{\partial p}{\partial q_{i}} q_{j}\right)\right] .
\end{gathered}
$$

The bracketed term on the right-hand side of equation (D.7) is the same as the bracketed term in first-order condition (D.6) that takes a value of zero in the optimum, which proves (D.4).

For Bertrand competition with differentiated products, the profit of firm $i$ (before paying $\rho F$ ) can be written as in (D.8), and its first-order condition as in (D.9). Equality (D.4) can be restated as in (D.10):

$$
\begin{gathered}
\hat{\pi}_{i}=\frac{1}{1-\alpha_{i} \alpha_{j}}\left[q_{i}\left(p_{i}, p_{j}\right) p_{i}+\alpha_{i} q_{j}\left(p_{j}, p_{i}\right) p_{j}\right] \\
\frac{\partial \hat{\pi}_{i}}{\partial p_{i}}=\frac{1}{1-\alpha_{i} \alpha_{j}}\left[\frac{\partial q_{i}}{\partial p_{i}} p_{i}+q_{i}\left(p_{i}, p_{j}\right)+\alpha_{i} \frac{\partial q_{j}}{\partial p_{i}} p_{j}\right]=0 \\
\frac{\partial \pi_{i, d}}{\partial \alpha_{i}}+\alpha_{i} \frac{\partial \pi_{j,-d}}{\partial \alpha_{i}}=\frac{\partial p_{i}^{R}}{\partial \alpha_{i}}\left[\left(\frac{\partial q_{i}}{\partial p_{i}} p_{i}+q_{i}\right)+\alpha_{i}\left(\frac{\partial q_{j}}{\partial p_{i}} q_{j}\right)\right]=0 .
\end{gathered}
$$

The bracketed term on the right-hand side of equation (D.10) is the same as the bracketed term in first-order condition (D.9) that takes a value of zero in the optimum, which proves (D.4).

In Bertrand competition with homogeneous products both firms set prices equal to marginal cost regardless of the values of $\alpha_{i}, \alpha_{j}$, which causes $\partial \pi_{i, d} / \partial \alpha_{i}=0$ and $\partial \pi_{j,-d} / \partial \alpha_{i}=0$. This proves (D.4).

Turning to the finding of main interest, using profit functions (D.1)-(D.3), the critical discount factor $\hat{\delta}_{i}^{*}$ can be written as in (D.11):

$$
\hat{\delta}_{i}^{*} \equiv \frac{\left(\pi_{i, d}-\pi_{i, k}\right)+\alpha_{i}\left(\pi_{j,-d}-\pi_{j, k}\right)}{\left(\pi_{i, d}-\rho F-\pi_{i, c}\right)+\alpha_{i}\left(\pi_{j,-d}-\rho F-\pi_{j, c}\right)} .
$$

One finds $\partial \hat{\delta}^{*} / \partial \alpha_{i}>0$ if inequality (D.12) is satisfied, which can be interpreted in the same way as inequalities (9) and (12) in the main text:

$$
\frac{\left(\pi_{i, k}-\rho F-\pi_{i, c}\right)\left(\pi_{i, d}-\pi_{j,-d}\right)}{\left(\pi_{i, d}-\pi_{i, k}\right)+\alpha_{i}\left(\pi_{j,-d}-\pi_{j, k}\right)}<\frac{\partial \pi_{i, c}}{\partial \alpha_{i}}+\alpha_{i} \frac{\partial \pi_{j, c}}{\partial \alpha_{i}} .
$$

To determine $\partial \hat{\delta}_{i}^{*} / \partial \alpha_{i}$, re-write $\hat{\delta}_{i}^{*}$ as follows: 


$$
\begin{aligned}
\hat{\delta}_{i}^{*} & =\frac{\hat{u}\left(\alpha_{i}, \alpha_{j}\right)}{\hat{v}\left(\alpha_{i}, \alpha_{j}\right)} \\
\text { with } \hat{u}\left(\alpha_{i}, \alpha_{j}\right) & =\left(\pi_{i, d}-\pi_{i, k}\right)+\alpha_{i}\left(\pi_{j,-d}-\pi_{j, k}\right)>0 \\
\text { and } \hat{v}\left(\alpha_{i}, \alpha_{j}\right) & =\left(\pi_{i, d}-\rho F-\pi_{i, c}\right)+\alpha_{i}\left(\pi_{j,-d}-\rho F-\pi_{j, c}\right)>0 .
\end{aligned}
$$

With the use of $\partial \pi_{i, k} / \partial \alpha_{i}=\partial \pi_{j, k} / \partial \alpha_{i}=0$ and (D.4), $\partial \delta_{i}^{*} / \partial \alpha_{i}$ can be written as in (D.14):

$$
\begin{aligned}
\frac{\partial \hat{\delta}_{i}^{*}}{\partial \alpha_{i}} & =\frac{\frac{\partial \hat{u}\left(\alpha_{i}, \alpha_{j}\right)}{\partial \alpha_{i}} \cdot \hat{v}\left(\alpha_{i}, \alpha_{j}\right)-\frac{\partial \hat{v}\left(\alpha_{i}, \alpha_{j}\right)}{\partial \alpha_{i}} \cdot \hat{u}\left(\alpha_{i}\right)}{\hat{v}\left(\alpha_{i}, \alpha_{j}\right)^{2}} \\
\text { with } \frac{\partial \hat{u}\left(\alpha_{i}, \alpha_{j}\right)}{\partial \alpha_{i}} & =\pi_{j,-d}-\pi_{j, k} \\
\text { and } \frac{\partial \hat{v}\left(\alpha_{i}, \alpha_{j}\right)}{\partial \alpha_{i}} & =\pi_{j,-d}-\rho F-\pi_{j, c}-\left(\frac{\partial \pi_{i, c}}{\partial \alpha_{i}}+\alpha_{i} \frac{\partial \pi_{j, c}}{\partial \alpha_{i}}\right) .
\end{aligned}
$$

Given $\hat{v}\left(\alpha_{i}, \alpha_{j}\right)>0$, the sign of $\partial \hat{\delta}^{*} / \partial \alpha_{i}$ is the same as that of its numerator as is shown in (D.15):

$$
\begin{aligned}
& \frac{\partial \hat{u}\left(\alpha_{i}, \alpha_{j}\right)}{\partial \alpha_{i}} \cdot \hat{v}\left(\alpha_{i}, \alpha_{j}\right)-\frac{\partial \hat{v}\left(\alpha_{i}, \alpha_{j}\right)}{\partial \alpha_{i}} \cdot \hat{u}\left(\alpha_{i}, \alpha_{j}\right)=\ldots \\
& \left(\pi_{i, k}-\rho F-\pi_{i, c}\right)\left(\pi_{j,-d}-\pi_{i, d}\right)+\left(\frac{\partial \pi_{i, c}}{\partial \alpha_{i}}+\alpha_{i} \frac{\partial \pi_{j, c}}{\partial \alpha_{i}}\right) \hat{u}\left(\alpha_{i}, \alpha_{j}\right) .
\end{aligned}
$$

This proves that $\partial \hat{\delta}^{*} / \partial \alpha_{i}$ is positive if inequality (D.12) applies.

The analysis of $\partial \hat{\delta}_{i}^{*} / \partial \alpha_{j}$ relies on condition (D.16):

$$
\frac{\partial \pi_{i, d}}{\partial \alpha_{j}}+\alpha_{i} \frac{\partial \pi_{j,-d}}{\partial \alpha_{j}}=0 .
$$

For Cournot competition with homogeneous products, (D.16) can be restated as in (D.17):

$$
\frac{\partial \pi_{i, d}}{\partial \alpha_{j}}+\alpha_{i} \frac{\partial \pi_{j,-d}}{\partial \alpha_{j}}=\frac{\partial q_{i}}{\partial \alpha_{j}}\left[\left(\frac{\partial p}{\partial q_{i}} q_{i}+p\right)+\alpha_{i}\left(\frac{\partial p}{\partial q_{i}} q_{j}\right)\right]=0
$$

The bracketed term on the right-hand side of equation (D.17) is the same as the bracketed term in first-order condition (D.6) that takes a value of zero in the optimum. For Bertrand competition with differentiated products, (D.16) can be restated as in (D.18):

$$
\frac{\partial \pi_{i, d}}{\partial \alpha_{j}}+\alpha_{i} \frac{\partial \pi_{j,-d}}{\partial \alpha_{j}}=\frac{\partial p_{i}}{\partial \alpha_{j}}\left[\left(\frac{\partial q_{i}}{\partial p_{i}} p_{i}+q_{i}\right)+\alpha_{i}\left(\frac{\partial q_{j}}{\partial p_{i}} q_{j}\right)\right]=0 .
$$


The bracketed term on the right-hand side of equation (D.18) is the same as the bracketed term in first-order condition (D.9) that takes a value of zero in the optimum. The equalities $\partial \pi_{i, d} / \partial \alpha_{j}=0$ and $\partial \pi_{j,-d} / \partial \alpha_{j}=0$ for Bertrand competition with homogeneous products also proves (D.16).

With respect to the second main result, inequality $\partial \hat{\delta}_{i}^{*} / \partial \alpha_{j}>0$ applies if inequality (D.19) is satisfied, whose interpretation is equivalent to that of (10) in the main text:

$$
0<\frac{\partial \pi_{i, c}}{\partial \alpha_{j}}+\alpha_{i} \frac{\partial \pi_{j, c}}{\partial \alpha_{j}} .
$$

To prove that $\partial \hat{\delta}_{i}^{*} / \partial \alpha_{j}>0$ applies under condition (D.19), consider that equation (D.20) provides that $\partial \hat{\delta}_{i}^{*} / \partial \alpha_{j}$ when assuming profit function (13) and defining $\hat{u}\left(\alpha_{i}, \alpha_{j}\right), \hat{v}\left(\alpha_{i}, \alpha_{j}\right)$ as in (D.13):

$$
\begin{gathered}
\frac{\partial \hat{\delta}_{i}^{*}}{\partial \alpha_{j}}=\frac{\frac{\partial \hat{u}\left(\alpha_{i}, \alpha_{j}\right)}{\partial \alpha_{j}} \cdot \hat{v}\left(\alpha_{i}, \alpha_{j}\right)-\frac{\partial \hat{v}\left(\alpha_{i}, \alpha_{j}\right)}{\partial \alpha_{j}} \cdot \hat{u}\left(\alpha_{i}, \alpha_{j}\right)}{\hat{v}\left(\alpha_{i}, \alpha_{j}\right)^{2}} \\
\text { with } \frac{\partial \hat{u}\left(\alpha_{i}, \alpha_{j}\right)}{\partial \alpha_{j}}=\left(\frac{\partial \pi_{i, d}}{\partial \alpha_{j}}-\frac{\partial \pi_{i, k}}{\partial \alpha_{j}}\right)+\alpha_{i}\left(\frac{\partial \pi_{j,-d}}{\partial \alpha_{j}}-\frac{\partial \pi_{j, k}}{\partial \alpha_{j}}\right) \\
\text { and } \frac{\partial \hat{v}\left(\alpha_{i}, \alpha_{j}\right)}{\partial \alpha_{j}}=\left(\frac{\partial \pi_{i, d}}{\partial \alpha_{j}}-\frac{\partial \pi_{i, c}}{\partial \alpha_{j}}\right)+\alpha_{i}\left(\frac{\partial \pi_{j,-d}}{\partial \alpha_{j}}-\frac{\partial \pi_{j, c}}{\partial \alpha_{j}}\right) .
\end{gathered}
$$

With the use of $\partial \pi_{i, k} / \partial \alpha_{j}=\partial \pi_{j, k} / \partial \alpha_{j}=0$ and (D.16), equation (D.20) can be simplified as is shown in equation (D.21):

$$
\frac{\partial \hat{\delta}_{i}^{*}}{\partial \alpha_{j}}=\frac{\left(\frac{\partial \pi_{i, c}}{\partial \alpha_{j}}+\alpha_{i} \frac{\partial \pi_{j, c}}{\partial \alpha_{j}}\right) \cdot \hat{u}\left(\alpha_{i}, \alpha_{j}\right)}{\hat{v}\left(\alpha_{j}\right)^{2}} .
$$

Given $\hat{u}\left(\alpha_{i}, \alpha_{j}\right)>0$ and $\hat{v}\left(\alpha_{i}, \alpha_{j}\right)>0$, the inequality $\partial \hat{\delta}_{i}^{*} / \partial \alpha_{j}>0$ applies if inequality (D.19) is satisfied.

As in the case of the common ownership profit function (1), it can be shown for the cross ownership profit function (13) that $\hat{\delta}_{i}^{*}$ can be raised more easily by an increase in $\alpha_{j}$ than by an increase in $\alpha_{i}$ : Inequality (D.19) is more easily satisfied than is (D.12). The left-hand side of (D.12) is positive and, thus, greater than the left-hand side of (D.19). Assuming symmetry $\left(\alpha_{i}=\alpha_{j}\right)$ before an asymmetric expansion of $\alpha_{i}$ or $\alpha_{j}$ takes place causes $\partial \pi_{i, c} / \partial \alpha_{i}=\partial \pi_{j, c} / \partial \alpha_{j}$ and $\partial \pi_{j, c} / \partial \alpha_{i}=\partial \pi_{i, c} / \partial \alpha_{j}$. Using this in combination with Lemmas 1 and 3, one can show that the right-hand side of (D.19) is weakly greater than that of (D.12). Both observations ensure that inequality (D.19) is more easily satisfied than (D.12).

\section{References}

Aubert, C., Rey, P., \& Kovacic, W. E. (2006). The impact of leniency and whistle-blowing programs on cartels. International Journal of Industrial Organization, 24, 1241-1266. 
Azar, J., Schmalz, M. C., \& Tecu, I. (2016). Anti-competitive effects of common ownership. Working Paper No. 1235, Ross School of Business.

Farrell, J., \& Shapiro, C. (1990). Asset ownership and market structure in oligopoly. The RAND Journal of Economics, 21, 275-292.

Flath, D. (1991). When is it rational for firms to acquire silent interests in rivals. International Journal of Industrial Organization, 9, 573-583.

Flath, D. (1992). Horizontal shareholding interlocks. Managerial and Decision Economics, 13, 75-77.

Foros, O., Kind, H. J., \& Shaffer, G. (2011). Mergers and partial ownership. European Economic Review, 55, 916-926.

Friedman, J. W. (1971). A non-cooperative equilibrium for supergames. The Review of Economic Studies, $38,1-12$.

Gilo, D., Moshe, Y., \& Spiegel, Y. (2006). Partial cross ownership and tacit collusion. The RAND Journal of Economics, 37, 81-99.

Harrington, J. E. (2017). The theory of collusion and competition policy. Cambridge, MA: The MIT Press.

Karle, H., Stahl, K. O., \& Klein, T. J. (2011). Ownership and control in a competitive industry. ZEW Discussion Papers 11-071, ZEW.

Kwoka, J. E. (1992). The output and profit effects of horizontal joint ventures. The Journal of Industrial Economics, 40, 325-338.

López, A. L., \& Vives, X. (2016). Cross-ownership, r\&d spillovers, and antitrust policy. Working Paper No. 5935, CESifo.

Malueg, D. A. (1992). Collusive behavior and partial ownership of rivals. International Journal of Industrial Organization, 10, 27-34.

Nain, A., \& Wang, Y. (2018). The product market impact of minority stake acquisitions. Management Science, 64(2), 825-844.

Ouimet, P. P. (2013). What motivates minority acquisitions? The trade-offs between a partial equity stake and complete integration. The Review of Financial Studies, 26, 1021-1047.

Reitman, D. (1994). Partial ownership arrangements and the potential for collusion. The Journal of Industrial Economics, 42, 313-322.

Reynolds, R. J., \& Snapp, B. R. (1986). The competitive effects of partial equity interests and joint ventures. International Journal of Industrial Organization, 4, 141-153.

Salop, S. C., \& O'Brien, D. P. (2000). Competitive effects of partial ownership: Financial interest and corporate control. Antitrust Law Journal, 67, 559-614.

Schmalz, M. C. (2018). Common-ownership concentration and corporate conduct. Annual Review of Financial Economics, 10, 413-448.

Shelegia, S., \& Spiegel, Y. (2012). Bertrand competition when firms hold passive ownership stakes in one another. Economic Letters, 114, 136-138.

Trivieri, F. (2007). Does cross-ownership affect competition? Evidence from the italian banking industry. International Financial Markets, Institutions \& Money, 17, 79-101.

Tzanaki, A. (2015). The legal treatment of minority shareholdings under EU competition law: Present and future. Essays in honour of professor panayiotis I (pp. 861-886). Kanellopoulos, Athens: Sakkoulas Publications.

Publisher's Note Springer Nature remains neutral with regard to jurisdictional claims in published maps and institutional affiliations. 